Artigo

\title{
Matemática difícil: discursos, muros e monstros
}

Difficult mathematics: speeches, walls and monsters

Matemáticas difíciles: discursos, muros y monstruos

\author{
Luana Rafaela da Silva Costa ${ }^{1}$ \\ (i) [0000-0003-1091-8985] \\ Simone Moura Queiroz ${ }^{2}$ \\ [0000-0002-3878-4619]
}

\section{Resumo}

Esta pesquisa apresenta um recorte de uma dissertação que perpassa por caminhos consonantes à Filosofia da Diferença, buscando a interseção desse plano de imanência com o plano da Educação Matemática. Utilizou-se para isso, principalmente as considerações teóricas de Foucault $(2008,2013)$, além de outros autores buscando por meio deles dialogar com a Educação Matemática. Como método de pesquisa utilizamos a cartografia da subjetividade, fazendo uso de mapas narrativos composto por entrevistas e desenhos, realizadas com dois professores de matemática e dois alunos do ensino fundamental anos finais. Objetivando uma abordagem pelos discursos habituais sobre a dificuldade em matemática, revelando a existência de um muro fictício que separa professores e alunos sobre as considerações sobre a disciplina, diante da consolidação de verdades e tramas que envolvem o ensinar e aprender, nessa dinâmica social produtora de saberes, poderes, discursos e verdades. Resultados que reforçaram como as considerações discursivas estão fortemente entrelaçadas em relação a matemática, produzindo muros e monstros que precisam ser reconsiderados.

Palavras-chave: Educação Matemática. Filosofia da Diferença. Discurso.

\begin{abstract}
This research presents an excerpt from a dissertation that crosses consonant Philosophy of Difference' $s$ way, seeking the intersection in between of immanence's plane and Mathematical Education's plane. For this purpose, it was used Foucault's $(2008,2013)$ theoretical considerations, in addition to other authors seeking through them to dialogue with Mathematics Education. As a research method we used the cartography of subjectivity, making use of narrative maps composed of interviews and drawings, made with two math teachers and two elementary school students. For a fair approach by the usual speeches about the difficulty of mathematics, showing a fictitious wall between teachers and students about the consideration of the subject of mathematics, in view of the consolidation of truths and plots, this involves teaching and learning in all social dynamics of knowledge, powers, speeches and truths. Results that reinforce how discursive considerations are closely intertwined in relation to mathematics, producing walls and monsters that needs to be reconsidered.
\end{abstract}

Keywords: Mathematics Education. Philosophy of Difference. Speech.

1 Ir.luanarafaela@gmail.com, Mestre em Educação em Ensino de Ciências e Matemática, Quipapá/Pernambuco/Brasil.

2 simonemq35@gmail.com, Doutora em Educação Matemática, Docente, Universidade Federal de Pernambuco/UFPE/CAA, Caruaru/Pernambuco/Brasil. 


\begin{abstract}
Resumen
Esta investigación presenta un recorte de una disertación que recorre caminos acordes con la Filosofía de la Diferencia, buscando la intersección de este plan de inmanencia con el plan de Educación Matemática. Se utilizaron las consideraciones teóricas de Foucault $(2008,2013)$, así como otros autores que buscaban dialogar con La Educación Matemática. Como método de investigación, utilizamos la cartografía subjetiva, utilizando mapas narrativos compuestos de entrevistas y dibujos, realizados con dos profesores de matemáticas y dos estudiantes de primaria en los últimos años. Se trata de acercarse a los discursos habituales sobre la dificultad de las matemáticas, revelando la existencia de un muro ficticio que separa a profesores y alumnos en las consideraciones del tema, ante la consolidación de verdades y tramas que implican la enseñanza y el aprendizaje, en esta dinámica social que produce conocimientos, poderes, discursos y verdades. Resultados que refuerzan cómo las consideraciones discursivas están fuertemente entrelazadas en relación con las matemáticas, produciendo muros y monstruos que deben ser reconsiderados.
\end{abstract}

Palabras claves: Educación Matemática. Filosofía de la Diferencia. Discurso.

\title{
1 Primeiros delineamentos
}

"Matemática é difícil", "matemática é chata", "matemática é para poucos", "quem gosta de matemática é mais inteligente", ... Esses são alguns exemplos de discursos que não costumam causar estranhezas, pois que tem sido considerações frequentes de muitos alunos em relação a matemática. Discursos incômodos para muitos professores, pois, essa naturalização contribui para considerar a aprendizagem de matemática algo muito distante, por vezes até impossível por parte de seus alunos.

Diante dessas considerações, encontramos nas teorizações da Filosofia da Diferença um caminho possível para uma discussão de modo a deslocar essas verdades tão bem estabelecidas, não apenas sobre a matemática, mas também sobre os sujeitos da educação e sobre o próprio discurso que os permeiam. Dessa maneira, esta pesquisa trata-se de um recorte dos resultados de uma dissertação, a qual buscou descrever essa influência discursiva habitual em relação a dificuldade em matemática, realizando a interseção desse plano de imanência com o plano da Educação Matemática, diante da consolidação de verdades e tramas que envolvem o ensinar e aprender, nessa dinâmica social produtora de saberes, poderes, discursos e verdades.

Para isso, utilizamos as teorizações de Foucault $(2008,2013)$ e outros autores, e como método de pesquisa a cartografia da subjetividade, tornando possível descrever o quanto o discurso é uma ferramenta subjetivadora que reforça a resistência em relação a matemática, considerando-a o monstro do componente escolar, criando ainda mais barreiras, contribuindo inegavelmente para reforçar a resistência de muitos alunos, favorecendo uma experiência desagradável com a disciplina. Bem como, apresentar a considerações de professores e estudantes sobre esse quadro de dificuldades e dobra de forças em relação a essas considerações tão habituais.

\section{Discursos, ressonâncias, naturalização e verdade}

Um dos caminhos apresentado pela dissertação marca a existência fictícia de um muro, o qual separa os que sabem matemática dos que não sabem, fronteira cada vez mais reforçada 
diariamente pelos discursos que os sustentam. Consideração essa, inspirada nos estudos de Lins (2004) que brilhantemente relacionou a matemática a monstros, descrevendo o quanto os monstros servem para pôr limites e regular os passos daqueles que ousem se aproximar. No caso, os monstros servem para policiar a entrada no Jardim do Matemático. Enquanto para uns o monstro é monstruoso, para outros o monstro é de estimação. Enquanto para os professores a matemática é fonte de deleite, para muitos de seus alunos é fonte de pavor. Mas, o que os impede de circular no jardim matemático?

Lins (2004) buscou esclarecer que a existência do muro, não significa que de um lado tenha monstros e do outros humanos, mas que há humanos dos dois lados. Entretanto, quem garante que o monstro exerça a função de impedir a circulação é próprio criador do monstro, quando diz a si mesmo, "não sei o que fazer", e aos outros "não há o que fazer". É justamente o estranhamento que o próprio sujeito põe no terreno do outro, que o impede de entrar lá. "Protegido" por um discurso regulador, subjetivado a manter-se afastado da monstruosa matemática e reforçando muros já existentes, pois, todos dizem que o monstro ali está, então ali se evita circular.

O discurso torna-se uma ferramenta subjetivadora por considerarmos o processo de subjetivação como modos capazes de afetar o sujeito diante de seus comportamentos e escolhas, podendo interferir nos seus gostos e interesses, por vezes não tão claros e perceptíveis. Embora possa haver uma possibilidade de rompimento desse processo (QUEIROZ, 2015). Essa resistência implica em dobrar forças ou seguir por rotas de fugas por desejar algo diferente do proposto.

Nessa perspectiva, encontramos em Foucault (2008) base para estudarmos a funcionalidade do discurso. Ao aprofundar esses estudos, passamos a compreender o quanto um discurso é resultado de um longo processo histórico, cultural e social. Todo discurso segue regularidades que autorizam e determinam o que será aceito socialmente. Foucault (2008) afirma que todo discurso é posto em funcionamento a partir daqueles que tem autorização de falar e por isso, tornam-se aceito facilmente, produzindo verdades, sendo reverberados socialmente e rapidamente compartilhados por aqueles que se reconhecem no dito. 0 funcionamento do discurso em Foucault (2013) apresenta um procedimento, uma maneira de entender a naturalização que possibilita construir novos posicionamentos diante dos conhecimentos que nos são direcionados.

Segundo Veiga-Neto (2007), seria um procedimento de escavação das camadas descontínuas do já pronunciado, discursos do passado, fragmentos, discursos já esquecidos, que se mesclam a realidade atual. Fazendo-nos pensar que remete apenas sobre as causas atuais, Foucault (2013) demonstrou preocupação em evidenciar como os sujeitos são efeitos discursivos. E esses estudos reativaram todas as nossas discussões e vivências sobre os discursos que perpassam a matemática, o não gostar, o ser difícil, e muitos outros dizeres, enunciados e discursos frágeis e robustos que sustentam a naturalização da matemática monstruosa.

O desenvolvimento do conhecimento matemático é marcado historicamente por uma regulação do conhecimento. Muitos são os momentos que marcam as restrições desses conhecimentos, seja o acesso privilegiado das classes dirigentes, ou a predominância do gênero masculino a frente dos inúmeros estudos, os compilados gregos sob o domínio do clero, as escolas pitagóricas formadas por sociedades secretas, marcada por rituais rigorosos durante os estudos, e inclusive a diferenciação das matemáticas práticas e abstratas 
direcionadas a classe intelectual e dirigente, entre muitas outras considerações (SILVA; MENDES, 2013; SILVEIRA, 2002).

De modo geral, não há registros que demonstrem preocupação em compartilhar os conhecimentos matemáticos descobertos nessas épocas. A sociedade sempre esteve aquém dos estudos, resultados e descobertas. Nas palavras de Foucault (2013), os conhecimentos circulavam em uma sociedade do discurso através dos procedimentos de controle, que tem a função de conservar ou produzir discurso que circulam em um meio fechado, limitando os indivíduos que poderiam ter acesso. Não seria essa uma forma de construir um muro?

Alinhar um estudo discursivo significa pensar os discursos como uma verdade constituída na sociedade, resultado de processos sociais de cada tempo. Para Foucault (2008) precisamos desprender-se de olhar o discurso apenas como um conjunto de signos, carregados de significados que remetem a algo, mas vê-lo como criador de significados, atribuidor de sentidos, produtor do próprio objeto. "[...] são práticas que formam sistematicamente os objetos que falam" (FOUCAULT, 2008, p. 55), práticas essas que põem em funcionamento a produção de conhecimentos, o sentido das coisas e a verdade sobre as coisas.

A problematização desse jogo, permite mapear os ditos sobre a matemática, nos mais diferentes contextos enunciativos. Procedimentos que levam interdições, proibições, regulações, separação, exclusão, rejeição, procedimentos de controle que determinam regras sobre a regularidade discursiva. De acordo com Silveira (2011), discursos representam ecos de sentidos pré-construídos com bases em fatos que marcaram a história do desenvolvimento dos conhecimentos matemáticos. Ao filiarem-se a esses discursos, os sujeitos tornam-se porta vozes, e essa filiação pode afetar os sentimentos em relação à matemática. Considerações históricas, reverberadas, contribuem para constituição da subjetividade, de modo que não se perceba a subjetivação.

Felizmente as condições de existência formada pelo conjunto de enunciados que formam o discurso e sua formação discursiva, não são fixas, assim outras verdades podem existir. Discurso se constitui em movimento. "[...] Existe uma verdade instalada que seleciona discursos passíveis ou não de circulação" (FERREIRA; TRAVERSINI, 2013, p. 216). É justamente por meio do discurso que encontramos uma estratégia analítica, a fim de desmontar essas verdades e entendê-las como verdades construídas, inventadas por uma rede determinada em virtude do poder.

É diante desse extenso campo que buscamos deslocar essa compreensão do discurso foucaultiano para a Educação Matemática, enunciados sempre correlacionados a outros, defendidos de acordo com as verdades de cada época, dentro de uma formação discursiva repleta de regras e normas, maneira capaz de produzir uma verdade. A verdade da "matemática difícil e monstruosa". Seguida de indagações sobre como destruir o monstro discursivamente? Ou como torná-lo dócil?

\section{Metodologia}

Objetivando tornar mais claro esse distanciamento investigamos a perspectiva sobre a matemática na visão de dois professores, um da rede municipal e outro da rede estadual de ensino do estado de Pernambuco, para isso foram propostos mapas narrativos. Segundo Behnken e Monteiro (2005, p. 1), conforme citado por Bovo (2011, p. 19), “[...] o mapa narrativo visa reconstruir espaços pessoais da vida dos entrevistados e a relevância subjetiva desses espaços. Para isso são utilizados o desenho, a cartografia - como complementação 
paralela - a biografia narrativa como formas de representação." O objetivo é compreender o entorno pessoal e como esses desenhos representam sentimentos, medos, desejos, angústias, frustações, etc. Os mapas narrativos são uma junção de desenho e narrativa, são formas de disparar uma entrevista, não focado nas respostas esperadas pelo pesquisador, mas na sensibilidade em compreender a condução obtida nas narrativas.

Durante a produção de mapas foram convidados dois professores e em seguida dois alunos, esses por serem mencionados por um dos professores como sujeitos que dobraram a força. Por terem apresentado dificuldades com a matemática e reverter esse quadro, sendo destaques em suas turmas, pelos ótimos desempenho na disciplina, inclusive por receber menção honrosa nas Olímpiadas de Matemática - OBMEP. Nomeamos os participantes da seguinte forma, Professores, Hi-tech e Reflexivo, e os alunos como Introvertido e Dedicada. Os nomes resultaram de uma característica marcante da personalidade dos sujeitos observado por nós, o que não anula a existência de outras características ou que, algumas vezes, assumissem outros comportamentos.

\section{Resultados e discussões}

Iniciamos pedindo aos professores que desenhassem o que significava matemática para eles e, em seguida, o que significaria a mesma matemática para seus alunos, começamos a enxergar o quanto os alunos na visão deles não conseguem estar no mesmo terreno que eles. Reflexivo, após pensar bastante por alguns minutos, começou sua representação da matemática para si, representada no desenho abaixo.

Desenho 1 - Representação da matemática para Reflexivo

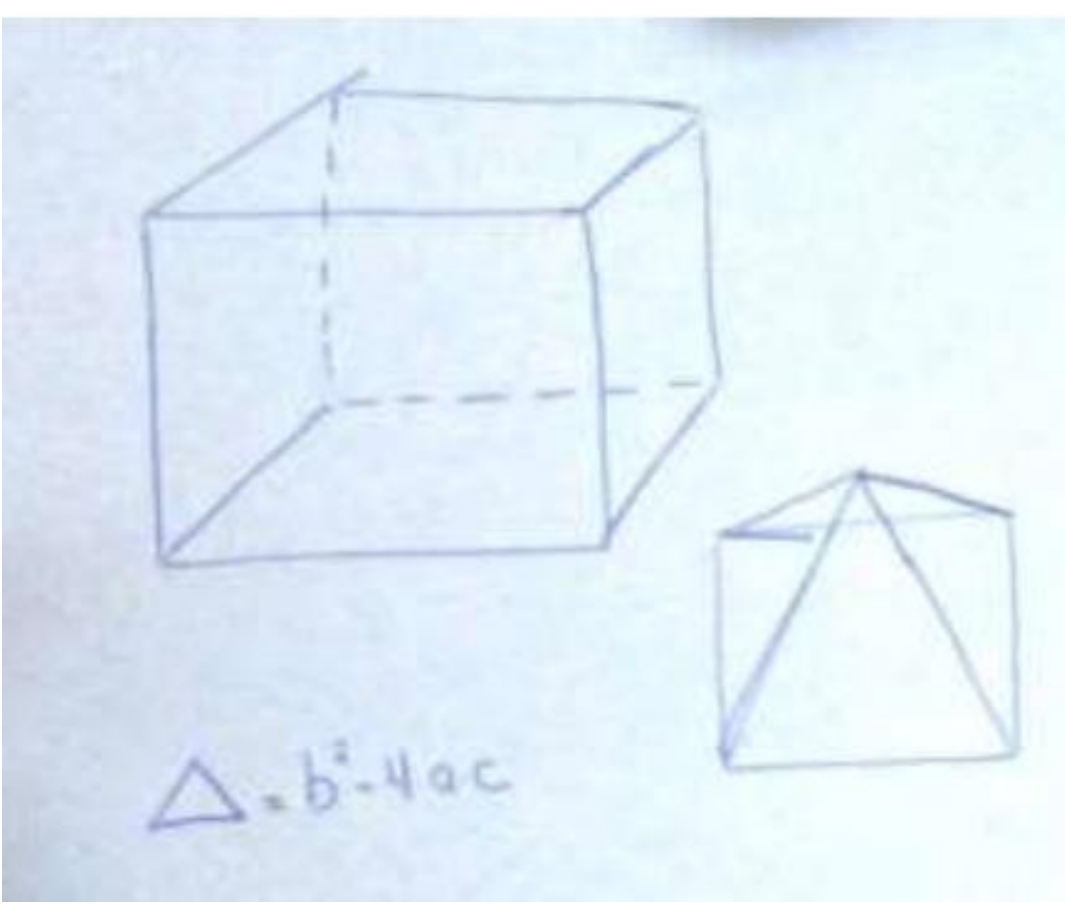

Fonte: Acervo da pesquisa, 2019.

Em relação ao desenho, Reflexivo utilizou formas geométricas espaciais, um cubo e uma pirâmide, além do símbolo $\Delta$, chamado de discriminante da função quadrática, utilizada na famosa fórmula de Bháskara. Não soube bem explicar o desenho. Porém, ao analisar o tamanho do cubo em relação as outras figuras, nos remete como a matemática ainda é 
pensada como uma caixa que separa seus conteúdos. Segundo Souza (2014), falta integração das áreas da matemática, resultado de um processo histórico desde 1808, quando a matemática foi fatiada em aritmética, álgebra, geometria e trigonometria. Para o autor, geralmente o professor tem grande dificuldade em fazer a unificação e integração entre uma área e outra, ainda que saibam bem os conteúdos separadamente. Segue o diálogo sobre o desenho:

Pesquisadora: Por que você desenhou um cubo?

Reflexivo: Não sei, foi a primeira coisa que me veio na cabeça quando fala de matemática, acho que é porque eu gosto mais de geometria do que da parte numérica.

Pesquisadora: E a fórmula?

Reflexivo: A segunda coisa, quando fala em matemática só vem na cabeça isso, formas geométricas ou alguma fórmula.

Pesquisadora: Quer desenhar mais alguma coisa?

Reflexivo: Não.

(Diálogo entre pesquisadora e professor, 2019).

Hi-tech, o segundo professor fez o seguinte desenho:

Desenho 2 - Representação da matemática para Hi-Tech

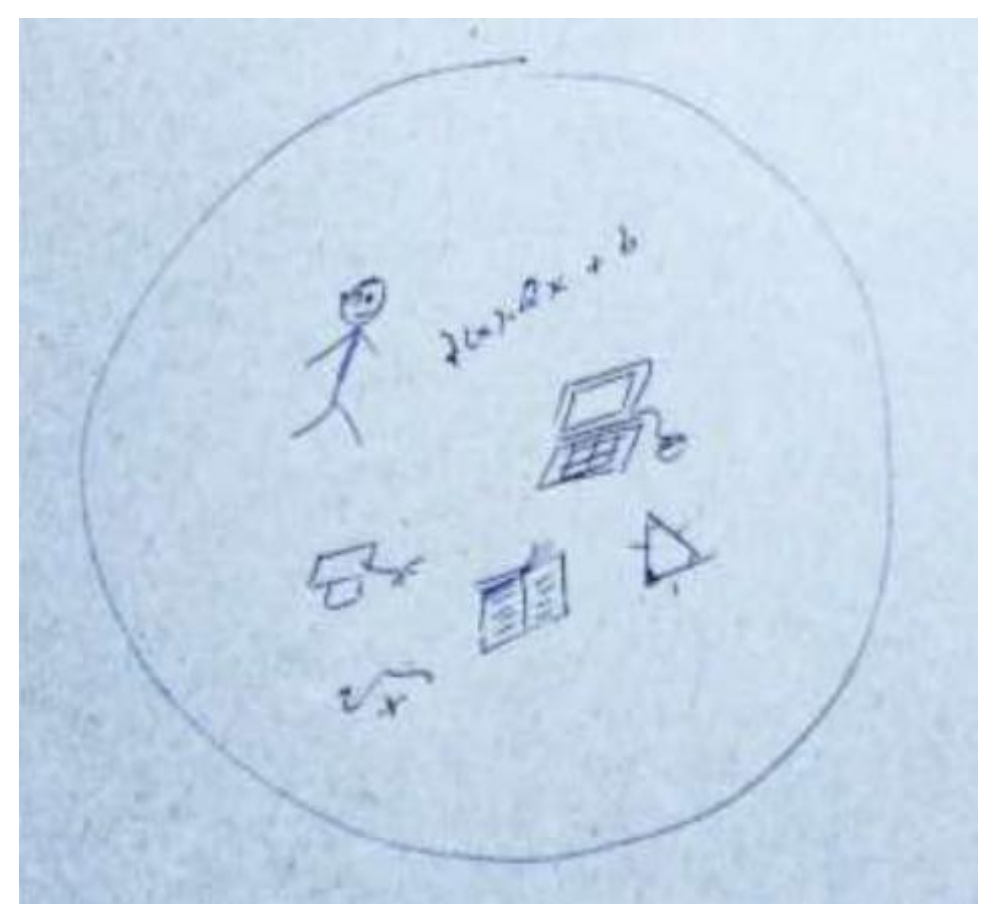

Fonte: Acervo da pesquisa, 2019.

Hi-tech realizou um conjunto de desenhos, composto por um sujeito, fórmula, computador, livro, uma figura geométrica e um capelo. Ele traz um conjunto de elementos que considerou estar ligados entre si. Nos dois desenhos dos professores apareceram as fórmulas como representantes da matemática. Hi-tech sempre demonstrou apreço pelas tecnologias, que considera ser um contribuinte para o ensino da disciplina. Segue o diálogo, após Hi-tech desenhar um círculo e permanecer olhando para o papel durante longos minutos.

Pesquisadora: O que significa esse círculo para você?

Hi-tech: Ainda não acabei, vou desenhar coisas nesse círculo. Vou desenhar uma pessoa, porque todos nós convivemos com a matemática, e embaixo as coisas que representam ela. 
Espera, vou desenhar um "chapéu" de formatura, porque na faculdade aprendi muitas coisas de matemática.

Pesquisadora: E na escola, e na rua, você aprendeu matemática?

Hi-tech: Aprendi, como disse nós convivemos com ela, mas foi uma matemática mais simples, na faculdade a gente aprende mais coisas, tem umas que não sei porque aprendemos, pois não usamos na sala de aula (começou a desenhar um computador).

Pesquisadora: E esse computador?

Hi-tech: Também vou desenhar um livro, porque é importante usar a tecnologia, mas também o livro é um recurso importante, acho que é o mais usado por todos. Vou desenhar uma raiz quadrada também, porque os alunos acham difícil quando a pessoa fala em raiz quadrada, mas quando ensinamos acha fácil, e fica dizendo só isso. Uma fórmula e um triângulo, pronto. Terminei.

Pesquisadora: Você gosta do assunto de função?

Hi-tech: Passamos muito tempo ensinando função que acabamos pensando nisso, por isso coloquei.

(Diálogo da pesquisadora com professor, 2019).

Após essa etapa que os professores representaram a matemática para si, pedimos aos dois que desenhassem alguma representação da matemática para seus alunos. Tivemos os seguintes registros.

Desenho 3 Representação da matemática para alunos - Reflexivo

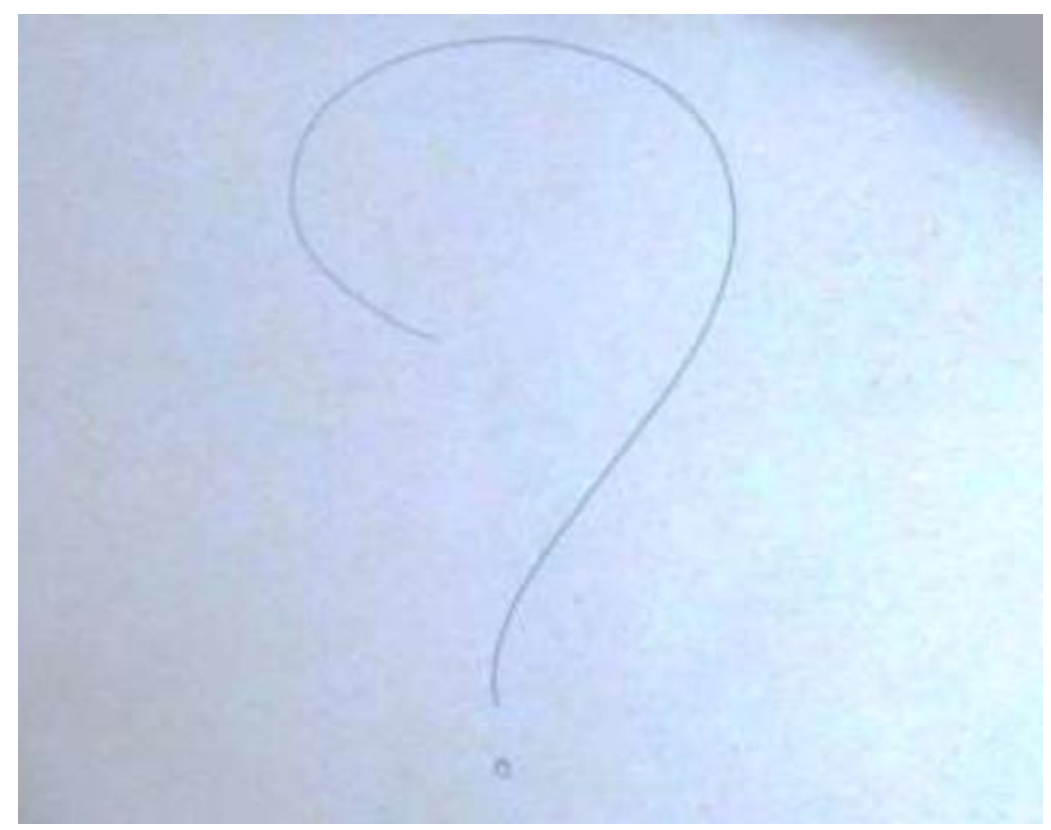

Fonte: Acervo da pesquisa, 2019.

Pesquisadora: Por que essa interrogação?

Reflexivo: Porque eu acho que quando os meninos pensam em matemática, eles têm mais dúvidas do que respostas.

Pesquisadora: E o que você acredita que acontece para que seus alunos tenham mais dúvidas que respostas?

Reflexivo: Eu acho que eles cresceram ouvindo que matemática é difícil, aí internalizaram isso na mente deles e criaram um bloqueio. Então, toda vez que eles olham para matemática antes mesmo de você explicar... Você só pensa em escrever qualquer coisa no quadro que eles já falam: "professor isso é muito difícil". Sem você ter falado nada ainda sobre o que eles vão aprender. 
(Diálogo da pesquisadora com professor, 2019).

Desenho 4 - Representação da matemática para alunos - Hi-Tech

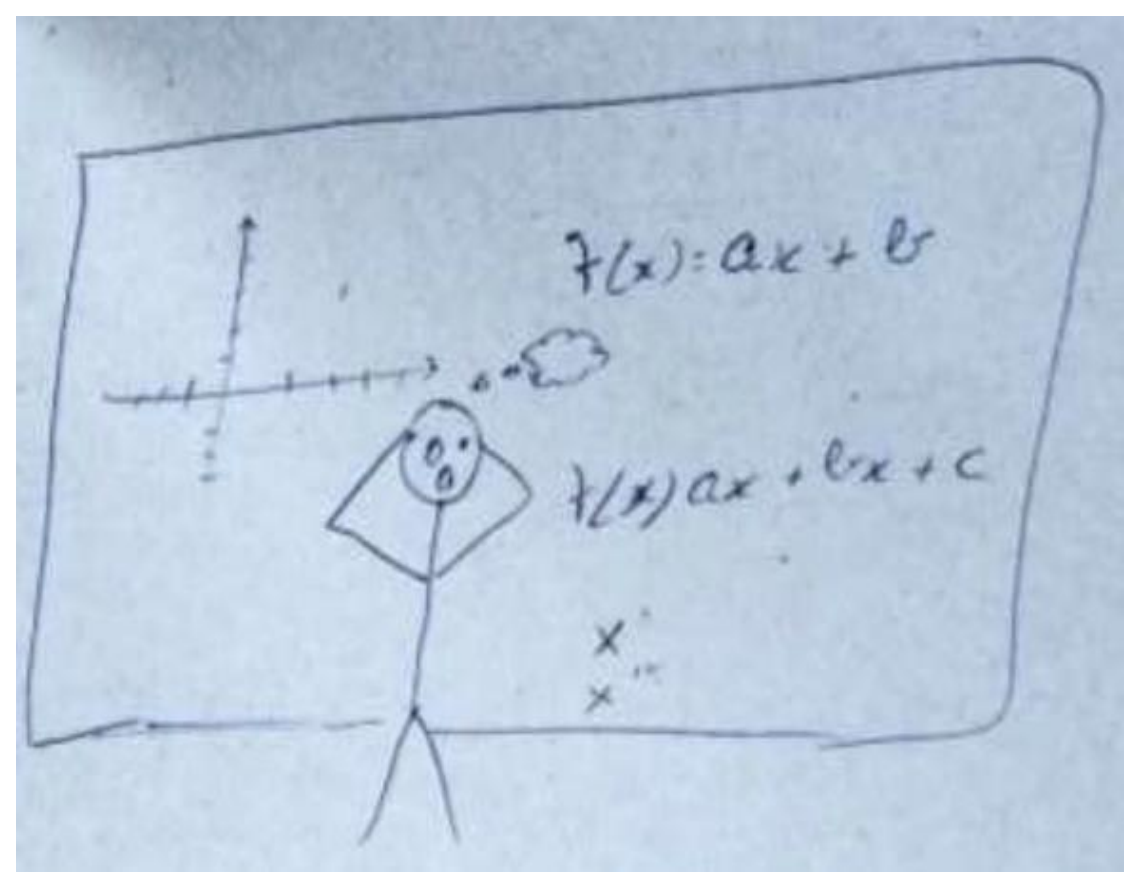

Fonte: Acervo da pesquisa, 2019.

Hi-tech: Já sei. Vou desenhar um aluno no quadro.

Pesquisadora: Nossa... ele está muito assustado.

Hi-tech: É, toda vez que chamo os alunos para o quadro eles fazem essa cara, no começo pensava que era a timidez de estar na frente dos colegas. Poucos são os que gostam de responder, os que veem são geralmente aqueles que tiram dez, tem bom desempenho, enquanto eles pedem para vir para o quadro os outros se escondem, ou fazem essa cara.

Pesquisadora: Por que você acha que isso acontece?

Hi-tech: Acho que é porque eles também não sabem do conteúdo, muitos não prestam atenção quando a gente explica, então junta tudo. Não sabem e não querem passar vergonha na frente dos amigos. Eu até parei mais de chamar eles no quadro.

Pesquisadora: E agora o que você usa para eles participarem?

Hi-tech: Explico, ando pela sala, vejo no caderno mesmo.

(Diálogo da pesquisadora com professor, 2019).

Enquanto a matemática para os professores foi relacionada a elementos que a compõe, para seus alunos foi remetida a naturalização da matemática difícil, produtor de um bloqueio ou medo, como afirma Reflexivo quando antes mesmo de ser apresentado o assunto a ser estudado. $O$ discurso é criador de significados, como afirmamos anteriormente segundo Foucault (2008), o discurso forma sistematicamente objetos que falam. Portanto, passam a ter efeito de verdade, isso deve ser entendido como um mecanismo de defesa sobre os sujeitos, e esse não tem como controlar os sentidos como um todo. Seja os alunos que passam a rejeitá-la ou seja o professor por considerar previamente que a disciplina será rejeitada. Segundo Costa e Queiroz (2019, p. 20),

[...] por estarmos tão habituados a ouvir que os alunos não gostam de Matemática, por considerá-la difícil, que esta ideia findou sendo 
absorvida como uma verdade incontestável, seja pelas vivências vistas nas escolas, seja diante as repetidas pesquisas comprobatórias repletas de discursos sociais.

Não resta, desse modo, muitos questionamentos, por considerá-la uma verdade. Perceba que, enquanto os professores representaram a matemática para si, por meio de figuras geométricas, fórmulas, etc., para seus alunos a representaram em forma de dúvidas e medo, muro que separam os professores e alunos. A matemática para os professores seriam monstros dóceis, e para os alunos monstros ferozes. Após esses desenhos, Reflexivo abordou a dificuldade em matemática por causa dessa perspectiva de crenças e filiação do discurso, como descrito abaixo.

Pesquisadora: Qual sua opinião sobre a consideração comum da matemática difícil?

Reflexivo: Acho que virou senso comum, já colocou na cabeça tanto isso que até para o professor, a gente acaba acreditando que a matemática é realmente mais difícil do que as outras disciplinas. Então, se é mais difícil, a gente tem a ideia, vamos focar mais em matemática e esquecer um pouquinho das outras. [...] A gente colocou na cabeça que a matemática e português é mais necessário do que ciências, história, geografia, aí já está estigmatizado isso. Então, por isso, ninguém diz, ah... vamos fazer de outro jeito, continua sempre assim. Faz tantos anos que é assim, então por que mudar agora?

Pesquisadora: No seu ponto de vista, qual o seu papel enquanto professor de matemática, tendo em vista essa dificuldade dos alunos?

Reflexivo: Primeiro eu acredito que o professor não deva só ensinar a matéria, o papel do professor vai além disso. O professor também é educador. Mas, a gente falando em matemática, acho que o primeiro passo é a gente mostrar aos alunos que não é coisa de outro mundo. Todo mundo pode aprender. Então, tem que tirar da cabeça que matemática é um dom, a gente acaba pensando isso. Tentar motivar o aluno. [...] Olha, você consegue, você pode, se você se esforçar, você não conseguiu fazer isso, consegue fazer isso também.

Pesquisadora: Você faz isso em sala?

Reflexivo: Não sempre, mas melhorei muito, antes eu era tipo bem racional, sabe? dizia: não aprendeu... não aprendeu porque não se esforçou o suficiente, hoje eu penso mais, se ele não aprender, busco descobrir o que é, busco um caminho diferente. Não é sempre. Tem aula que tiro para fazer uma roda, vamos conversar, sobre o que vocês querem, porque vocês acham isso difícil? Em alguns produz efeito, em outros, não. Alguns dizem: "realmente eu posso".

Pesquisadora: Há casos de alunos com baixo desempenho em matemática e que tenham melhorado em suas aulas após essas intervenções?

Reflexivo: Sim... tenho dois alunos, que eles... inclusive os dois, eles são repetentes, se não me engano. E esse ano eles conseguiram passar em duas etapas das olimpíadas de matemática. Eles não acreditaram de jeito nenhum, até eles ficaram surpresos, quando foram para a segunda fase.

Pesquisadora: *nesse momento entendi o que faz o corpo vibrar, continuei a fazer perguntas sobre esses alunos*. Após esse acontecimento, mudou a relação deles na sala de aula? Como era o comportamento deles?

Reflexivo: Pronto... eles até começaram a meio que ser ajudantes (monitores), eles tinham muita dificuldade, mas quando eles viram, eles achavam que tinham. Mas, quando perceberam que podiam fazer mais e que era simples, às vezes diziam: "não faz desse jeito, aos colegas". Não sei se fui eu que motivei, mas alguma coisa os motivou.

Pesquisadora: Eles ainda são seus alunos?

Reflexivo: Sim.

Pesquisadora: Você concederia um momento para que eu falasse com eles sobre a pesquisa? 
Reflexivo: Sim.

(Diálogo da pesquisadora com professor, 2019).

Com isso, fomos investigar a percepção dos alunos em relação a matemática. Ao serem perguntados sobre a relação com a matemática, o gostar da disciplina, obtivemos o seguinte diálogo.

Pesquisadora: Vocês se consideram alunos que sempre gostaram de matemática ou passaram a gostar, ou não gostam? Como vocês descrevem a relação de vocês com a disciplina de matemática.

Introvertido: Sempre gostei de matemática.

Dedicada: Eu não gostava muito, mas eu estou começando a gostar melhor, só que é um pouco complicado.

Pesquisadora: O que fez você começar a gostar de matemática?

Dedicada: Antes eu não tinha tanto interesse em matemática. Achava chato, não me esforçava tanto, mas toda vida fui esforçada. Aí depois fui descobrindo que a matemática, você pode ser amiga da matemática, e pode chegar no resultado, é chato quando a conta demora muito, $e$ você não está descobrindo o valor. Agora eu acho legal resolver problemas, pensar, quebrar a cabeça.

Introvertido: Muito bom resolver contas.

Dedicada: Alegria maior é quando você consegue resolver aquela conta que estava muito difícil e você conseguiu, uhuhuhu (comemorando e sorrindo), eu consegui resolver.

Introvertido: Eu nunca tive dificuldades.

Pesquisadora: Você considera que estuda mais que seus colegas, por isso não tem dificuldades? Introvertido: Eu sempre gostei, quando eu chegava em casa, eu sempre brinquei de matemática com meu pai, porque é bom em matemática também. E também presto muita atenção nas aulas. Algumas coisas são complicadas, mas quando o professor ensina direito dá para aprender.

Pesquisadora: Por que vocês acham que muitos colegas de vocês têm dificuldade em aprender? Introvertido: Preguiça.

Dedicada: Preguiça, e outros é que tem dificuldades, e não tem muita lógica de pensar rápido. Demora um pouco a raciocinar e acaba achando chato e acaba desistindo.

Pesquisadora: Vocês acham que se eles persistissem um pouco mais, se eles tivessem mais tempo, eles conseguiriam?

Introvertido e Dedicada: Sim.

Pesquisadora: Vou pedir para que vocês façam um desenho, tudo bem? Aqui tem papel, tem lápis, canetas e lápis de cores, podem utilizar à vontade. Façam um desenho do que significou o momento em que souberam que tinham passado nas primeiras fases das olímpiadas de matemática. $O$ que significou para vocês? Ou até mesmo um desenho que represente $o$ momento em que vocês tiram notas boas na escola...

Dedicada: Alegria.

Introvertido: Só passamos em duas etapas...

*(nessa entrevista, a escola ainda não tinha recebido os resultados da última etapa, quando os alunos receberiam uma menção honrosa pelos seus desempenhos). *

Pesquisadora: Você está triste?

Introvertido: Gostaria de ter passado.

Pesquisadora: Mas, matemática é persistência. Vocês têm um longo caminho pela frente.

Dedicada: Primeira vez que eu tinha passado numa olímpiada de matemática, eu fiquei surpresa, fiquei questionando, sério, eu passei? Não acredito, não. Vou desenhar uma carinha de alegria, de surpresa. Só que não sei desenhar.

Introvertido: Alegria... 
Dedicada: As olimpíadas de matemática é uma das maiores do mundo, e tipo, eu estar entre um dos classificados, foi uma surpresa.

Introvertido: **desenhando um troféu**

Pesquisadora: Representa um prêmio para você?

Introvertido: Eu só pensava em terminar, para ver se ganharia o prêmio, curiosidade até o fim. Dedicada: Uma vitória.

(Diálogo da pesquisadora com alunos participantes, 2019).

Desenho 5 - Representação de passar nas fases da OBMEP - Dedicada

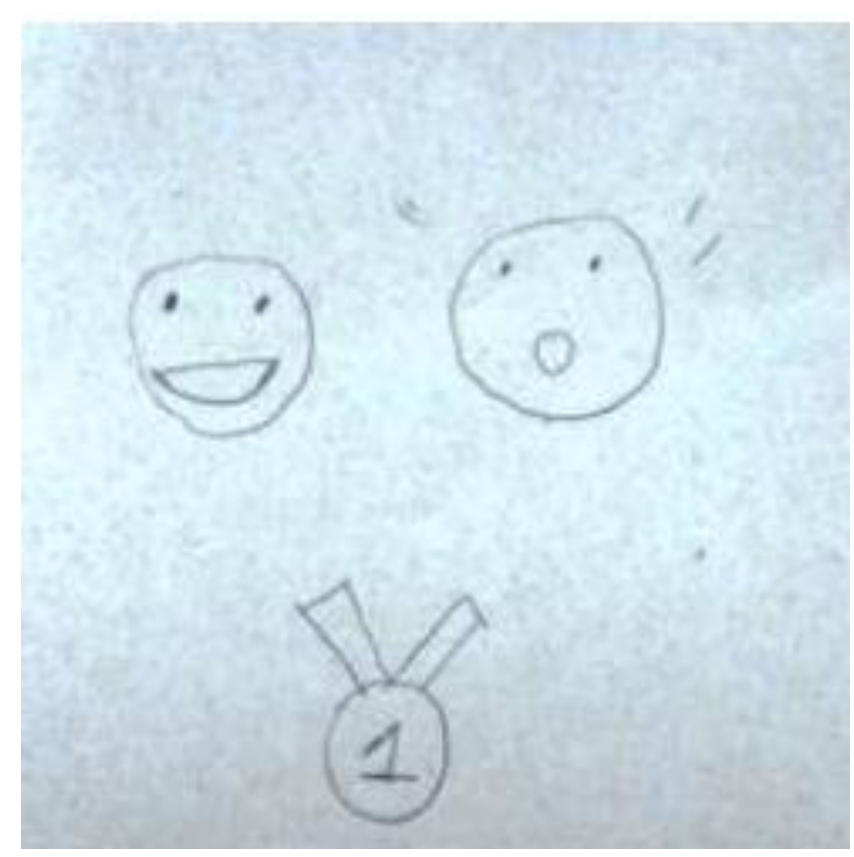

Fonte: Acervo da pesquisa, 2019.

Desenho 6 - Representação de passar nas fases da OBMEP - Introvertido

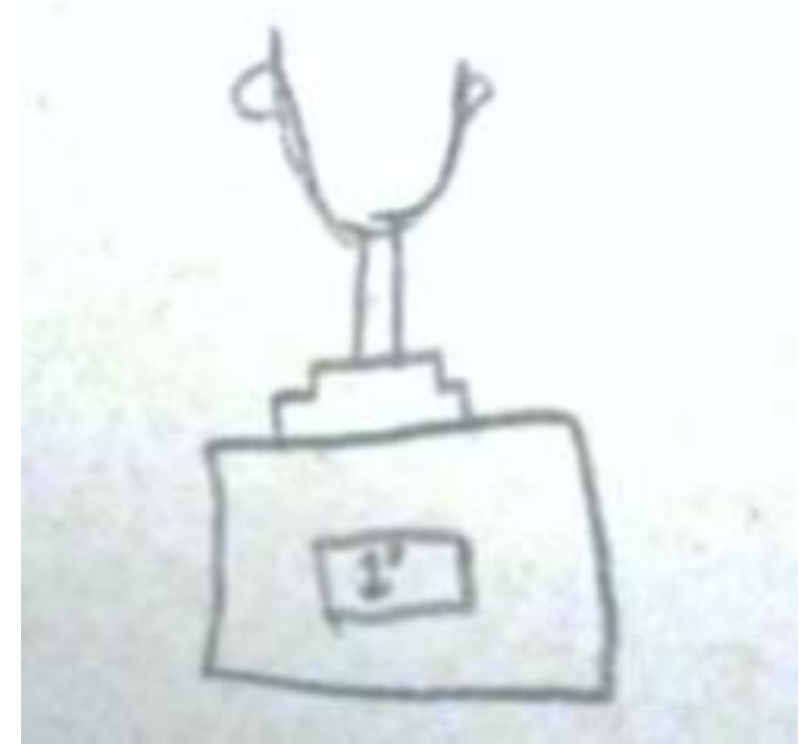


Fonte: Acervo da pesquisa, 2019.

Vejamos o quanto os alunos retrataram esse momento como uma grande conquista, que representa alegrias, surpresas e curiosidade. O desenho dos alunos representando a medalha e o troféu trazem o algarismo um, a posição de primeiro lugar, lugar que já representam na sala de aula, por se relacionarem tão bem com a disciplina. Essas considerações nos remeteram aos registros históricos sobre a escola pitagórica, onde "[...] a Matemática ganha status de rainha das ciências, pois estabelece que tudo no universo é regido pelo número" (SILVA; MENDES, 2013, p. 5).

Essa relação foi estabelecida pelas aproximações matemáticas com os fenômenos naturais, fazendo os pitagóricos acreditarem que Deus criou tudo por meio de números, movimento dos planetas, som, luz, enfim, tudo que poderia ser explicado por meio de números. O lema dos pitagóricos era "tudo é número". A relação que estabelecemos é: o quanto o status de rainha das ciências confere àqueles que se dedicam a estudar e conseguem também um certo status, ser bom na rainha das ciências significa vitória, destaque.

Quando o aluno se refere a apenas passar em algumas etapas, remete ao rompimento da fronteira do monstro matemático, passando pela fronteira e agora podendo passear no jardim dos matemáticos; o troféu e a medalha representam esse momento de vencer o monstro, agora para eles o monstro também é dócil, o que também não significa que eles não tenham dificuldade com a disciplina, como veremos adiante.

Segundo Foucault (2013) ao atentar-se sobre o dito, encontramos além do sujeito enunciador, regras não explicitas que autorizam quem fala, que posições institucionais ocupa o enunciador, entre outras diversas regras de enunciação. Perceba o quanto esses alunos, ganham certa autoridade, eles agora circularem no jardim matemática, os confere certo poder, agora determina o que é preciso para conquistar esse espaço. Afirmando que precisa estudar muito, que seus colegas tem preguiça, etc., como apresenta o diálogo anterior. Possuem uma autoridade discursiva que lhe pertence por não temer mais o monstro, embora apresentem que não estão isentos de algumas dificuldades na disciplina, como retrata o diálogo abaixo.

Reflexivo: Como foi a entrevista de vocês? Vocês também tiveram que desenhar? Introvertido: Sim, fui logo dizendo, eu não sei desenhar muito bem, não.

Dedicada: Eu gostei, desenhei umas coisas legais.

Reflexivo: O que ela pediu para vocês desenharem?

Dedicada: Conversamos sobre como nos sentimos com a matemática. Depois, pediu para que nós desenhássemos o que significaria a matemática para nós. Eu pensei logo em números, em contas, não em letras. Olha meu desenho: 


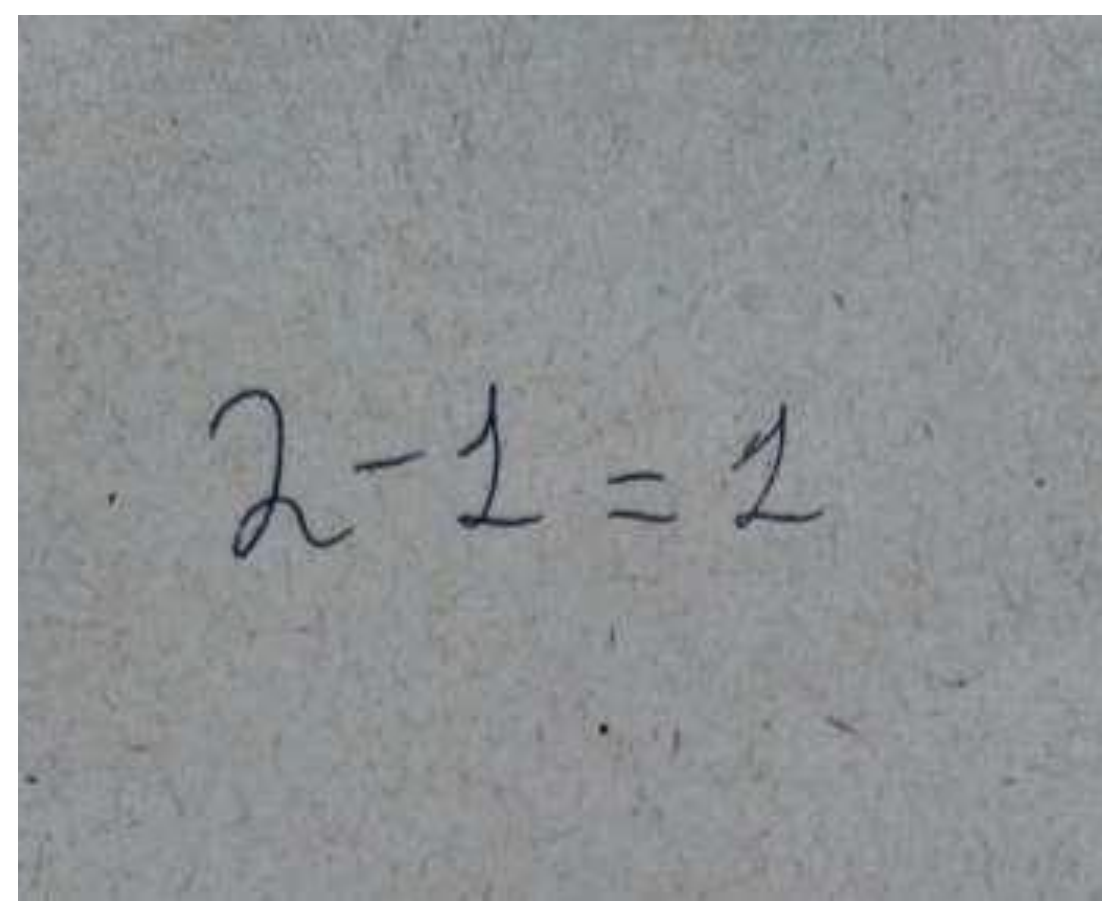

Fonte: Acervo da pesquisa, 2019

Introvertido: Eu também, fiz um número bem grande. Fui logo dizendo, também não gosto de letras. Porque quando vai colocando letras fica mais difícil de resolver, mais demorado. Olha o meu:

Desenho 8 - Representação da matemática para Introvertido

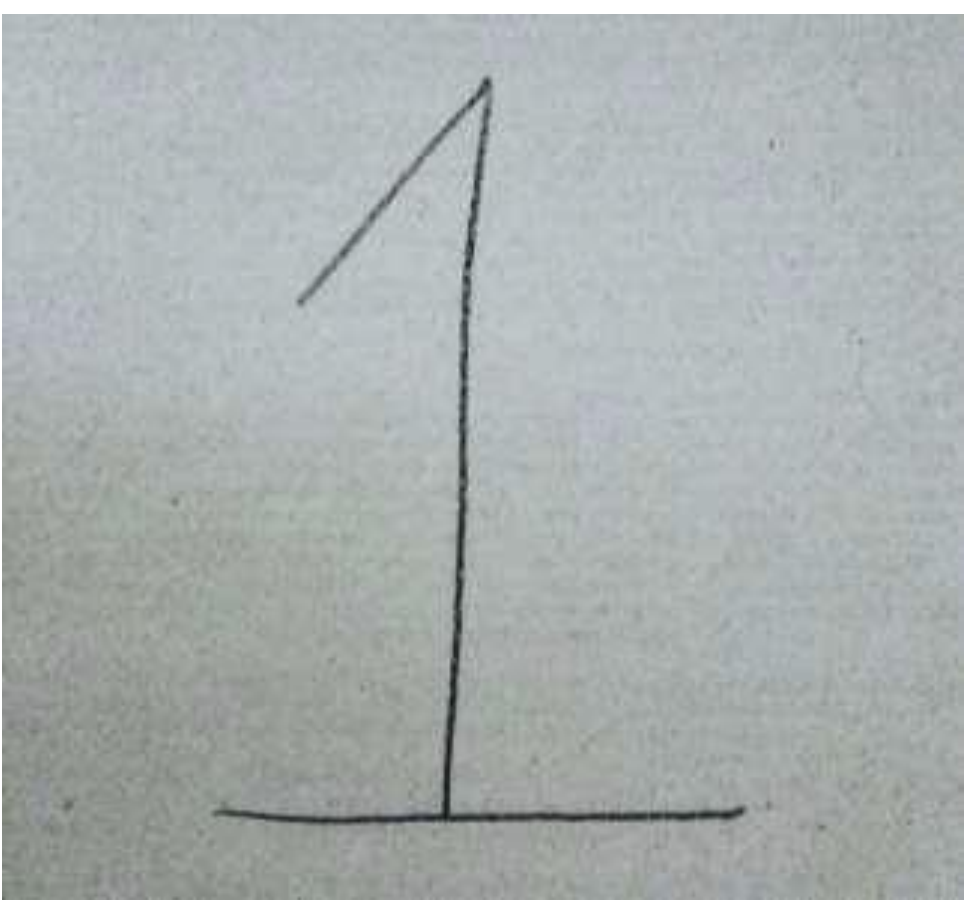

Fonte: Acervo da pesquisa, 2019

Reflexivo: Vocês falaram mal das letras?

Dedicada: Ela perguntou professor, se a gente tinha dificuldade com Álgebra.

Introvertido: Disse que não gostava, porque vai ter que pegar a letra, descobrir o que 
essa coisa significa para descobrir outras, fica calculando, calculando....

Dedicada: É bem complicado descobrir o valor desconhecido. Quando são letras iguais é mais fácil, mas quando mistura letras diferentes, aí fica mais complicado.

Introvertido: Para mim é fácil, mas o que não gosto é que demora muito para resolver. É isso que eu não gosto.

Reflexivo: E olha que temos muitas letras ainda.

(Diálogo entrelaçado de alunos e professores, 2019).

De acordo com Gil (2008), a linguagem algébrica e a resolução de problemas são momentos em que o aluno se depara com um cenário novo e, algumas vezes, esses procedimentos são contraditórios e menos lógicos que os procedimentos aritméticos, aos quais estavam acostumados. A álgebra apresenta grande utilidade para o desenvolvimento do conhecimento matemático, entretanto, muitos alunos não conseguem apropriar-se dos conceitos e procedimentos algébricos, gerando desinteresse e resistência por seu estudo.

Segundo Booth (1995), a álgebra é geradora de confusões e atitudes negativas consideráveis entre os alunos, outra dificuldade apresentada é a interpretação dos símbolos operatórios, o uso de letras para indicar valores desconhecidos, e dependendo da expressão, essa letra ainda pode variar o seu valor. Para que a aprendizagem aconteça é preciso que o aluno compreenda a ideia de variável, portanto, é preciso assimilar dois processos: a generalização e a simbolização.

[...] para que realmente se construam conceitos e se aproprie de forma efetiva dos procedimentos algébricos, é fundamental que se consiga produzir significados para o seu estudo no entanto percebo que o trabalho com o estudo algébrico não vai muito adiante de manipulações de símbolos que na maioria das vezes não possuem nenhum significado, sendo o seu estudo desenvolvido de forma mecânica (GIL, 2008, p. 40).

Outro estranhamento comum é sobre o sistema simbólico, linguagem própria da matemática. "Começo com uma ideia apresentada por nosso colega Roberto Baldino, que considera que a Matemática dos matemáticos seja resultado de um esforço (processo histórico) de colar significados a significantes" (LINS, 2004, p. 95). A determinação simbólica não tem razão natural, mas assim foi definida, uma definição constitutiva, o matemático ao definir um objeto não cabe a discussão se esta definição corresponde a algo fora da própria matemática, a discussão é pautada em se a definição simbólica ajuda a estabelecer novas relações que esclareçam problemas já postos.

Costa e Queiroz (2019) ao realizarem um estudo com os alunos que declararam gostar de matemática, puderam verificar o quanto os que são considerados privilegiados, não estão isentos da dificuldade em matemática, inclusive sentem-se desafiados a superar as possíveis dificuldades apresentadas. Não se consideram gênios, nem privilegiados, e justificaram sua relação positiva com a disciplina pela dedicação e prática, considerando esses fatores como uma responsabilidade própria. A escola como um espaço de produção de saber e poder, coloca em prática a ideia comum, naturalizada pelos alunos com dificuldade e, com isso, os próprios professores são efeitos desses discursos.

\section{Considerações}

A investigação nos leva a compreender o quanto o discurso negativo está intrínseco na perspectiva de alunos e professores sobre a matemática. Fato histórico, repaginado aos fatores atuais, por vezes, os próprios professores não percebendo contribuem indiretamente 
de modo a reafirmar esse muro e a criação de monstros fictícios quando de ante mão considera que seus alunos terão medo, pavor e etc. enquanto eles relacionam bem com a matemática e seus elementos. Inclusive os alunos, quando se tornam enunciadores do discurso e com isso, passam a ter autoridade, reverberando a falta de engajamento de seus colegas, como fator decisivo para aprender a disciplina.

Um dos fatos interessantes, é que esses mesmos alunos, considerados os destaques na sala de aula, também apresentam dificuldades gerais em determinados áreas, como a manipulação algébrica, por exemplo, porém, consideram que a persistência, ou seja a dobra da força, é necessária para torna-se "amigo(a)" da matemática, inclusive sentem-se desafiados a resolver os problemas propostos, citando os bons resultados como reflexos de uma responsabilidade própria. Importante também as considerações que os professores apresentaram, sobre motivar seus alunos, ir de encontro com a compreensão geral de que não conseguem. Se a legitimação do discurso ocorre através da reverberação compartilhadas e aceitas, talvez seja essa uma possibilidade de enfraquecer o monstro e rever os muros até então inexorável dessa matemática tão aversiva. Uma oportunidade para enunciar uma matemática mais acessível, mais dócil, um jardim cada vez mais habitável, com cada vez menos muros e monstros.

\section{Referências}

BOOTH, Lesley R. Dificuldades das crianças que se iniciam em álgebra. In: COXFORD, Arthur F. e SHULTE, Albert P. As ideias da Álgebra. São Paulo: Atual, 1995.

BOVO, Audria Alessandra. Abrindo a caixa preta da escola: uma discussão acerca da cultura escolar e da prática pedagógica do professor de Matemática. 2011. 184f. Tese (Doutorado em Educação Matemática) - Instituto de Geociências e Ciências Exatas, Universidade Estadual Paulista, Rio Claro, 2011.

COSTA, Luana Rafaela Silva; QUEIROZ, Simone Moura. O gostar de matemática: Discurso, desejo e marca. In: Maria Fernanda dos Santos Alencar; Marcelo Henrique Gonçalves de Miranda; Maria Fabiana da Silva Costa; (Org.). Educação, estado e diversidade: perspectivas e desafios. 1 ed. Recife: Editora UFPE, v. 5, p. 17-37, 2019.

FERREIRA, Maurício dos Santos; TRAVERSINI, Clarice Salete. A análise Foucaultiana do Discurso como ferramenta metodológica de pesquisa. Educação \& Realidade, Porto Alegre, v. 38, n. 1, p. 207-226, jan./mar. 2013.

FOUCAULT, Michel. A arqueologia do saber. 7 ed. Rio de janeiro: Forense Universitária, 2008.

FOUCAULT, Michel. A ordem do discurso: aula inaugural no Collège de France, pronunciada em 2 de dezembro de 1970/Michel Foucault. Trad. de Laura Fraga de Almeida Sampaio. 2 ed. São Paulo: Edições Loyola, 2013.

GIL, Katia Henn. Reflexões sobre as dificuldades dos alunos na aprendizagem de álgebra. 2008. 118f. Dissertação (Mestrado em Educação em Ciências e Matemática) - Fac. De Física, PUCRS. Porto Alegre, 2008.

LINS, Romulo Campos. Matemática, Monstros, Significados e Educação Matemática. In: Educação 
matemática: pesquisa em movimento/ Maria Aparecida Viggiani Bicudo, Marcelo de Carvalho Borba. São Paulo: Cortez, 2004.

QUEIROZ, Simone Moura. Movimentos que permeiam o devir professor de matemática de alguns licenciandos. 2015. 208f. Tese (Doutorado em Educação Matemática) - Instituto de Geociências e Ciências Exatas, Universidade Estadual Paulista, Rio Claro, 2015.

SILVA, Maria Deusa Ferreira da; MENDES, Iran Abreu. A intencionalidade no fazer matemática: um paralelo entre os "discursos" da história e a sociologia da matemática. In: Revista Brasileira de História da Matemática. v. 13, n., 27, p. 33-53. Publicação Oficial da Sociedade Brasileira de História da Matemática, 2013.

SILVEIRA, Marisa Rosâni Abreu da. Matemática é difícil: Um sentido pré-constituído evidenciado na fala dos alunos. 2002. Disponível em:

http://www.anped.org.br/25/marisarosaniabreusilveirat19.rtf Acesso em: 30 de jun. de 2018.

SILVEIRA, Marisa Rosâni Abreu da. A dificuldade da Matemática no Dizer do Aluno: ressonâncias de sentido de um discurso. Educ. Real., Porto Alegre, v. 36, n. 3, p. 761-779, set./dez. 2011.

Disponível em: <http://www.ufrgs.br/edu_realidade>

SOUZA, José Romenelli. Ensinando integramente aritmética, geometria e álgebra: propostas de atividades para a matemática do ensino fundamental. 2014. 58f. Monografia (Licenciatura em Matemática/EaD) - Universidade Federal da Paraíba, Taperoá - PB, 2014.

VEIGA-NETO, Alfredo. Foucault \& a educação. 2 ed. 1 reimp. Belo Horizonte: Autêntica, 2007. 